\title{
SHOCK COMPRESSION OF ARAGONITE AND IMPLICATIONS FOR THE EQUATION OF STATE OF CARBONATES
}

\author{
Joana Vizg1rda and Thomas J. Ahrens
}

Seismological Laboratory, California Institute of Technology, Pasadena, California 91125

Abstract. Hugoniot equation of state and release adiabat results are presented for c cut crystals of aragonite, the high-pressure polymorph of calcite, shocked to pressures of up to $40 \mathrm{GPa}$. A Hugoniot elastic limit is observed at $2.5 \pm 0.8 \mathrm{GPa}$ and is similar to that of calcite, which, depending on orientation, ranges from 1.5 to $2.5 \mathrm{GPa}$. A phase transition, possibly displacive, occurs between 5.5 and $7.6 \mathrm{GPa}$. Above shock pressures of $\sim 10 \mathrm{GPa}$, the aragonite and calcite Hugoniots are nearly colncident, suggesting transformation of both polymorphs to the same phase. Model calculations, attempting to characterize the high pressure $\mathrm{CaCO}_{3}$ phase are presented. Aragonite release adiabats centered at pressures between 9 and $14 \mathrm{GPa}$ indicate that states with apparent zero-pressure densities from 2.9 to $3.2 \mathrm{~g} / \mathrm{cm}^{3}$ are achieved upon decompression from progressively greater shock pressures. Observed unloading paths from shock pressures above $17 \mathrm{GPa}$ are significantly and consistently shallower (in a density-pressure plane) than those from lower pressures, and zero-pressure densities up to $20 \%$ below that of the initial aragonite density are achieved upon unloading; these features suggest that vaporization is occurring upon unloading. According to theoretical shock temperature and entropy calculations, however, the minimum shock pressure for vaporization upon release for aragonite is $55 \mathrm{GPa}$ (and $33 \mathrm{GPa}$ for calcite), significantly higher than the observed value.

\section{Introduction}

Compressive behavior in the $\mathrm{CaCO}_{3}$ system has generated interest since Bridgman's [1939] discovery of two low-pressure phase transitions in calcite. While subsequent static and dynamic compression studies have extended the calcite pressure-density field to $94 \mathrm{GPa}$ [Huang and Wyllie, 1976; Ahrens et al., 1966; Adadurov et a1., 1961; Kalashnikov et al., 1973] only limited compressibility data exist on its high-pressure polymorph, aragonite. The static experimental results on aragonite by Bayuk et al. [1974] and Jamieson [1957] are limited to pressure of 1.5 and $2.4 \mathrm{GPa}$, respectively; until the present investigation, no shock compression aragonite data have been available.

The purpose of this investigation is two-fold: first, to determine the shock compression curve of aragonite, identify any possible phase transitions, and speculate as to their nature and to compare it to the calcite Hugoniot, and second, to measure release isentropes for aragonite and thus gain insight into the behavior upon release from shock pressure of carbonates in general.

Copyright 1982 by the American Geophysical Union.

Paper number 1B1460.

0148-0227/82/001B-1460\$05.00
The investigation of shock compression and release behavior of carbonates has direct application to descriptions of cratering mechanics and impact metamorphism of rocks containing carbonate minerals. Approximately $30 \%$ of the known or probable terrestrial meteorite impact craters occur at least partially in carbonate rocks [Grieve and Robertson, 1979]. Also, carbonate rocks may compromise a significant portion of the cratered Martian surface [Booth and Kieffer, 1978], and have been suggested as being the primary phases which determine the partial pressure of $\mathrm{CO}_{2}$ on the surface of Venus [Lewis, 1970]. In addition, a large class of craters for which energies are approximately known, the Pacific Test Site nuclear craters, were formed in calcite- and aragonite-containing coralline limestone. The shock compression and release data presented in this paper will be useful in understanding impact and explosion processes in these various carbonate terrains. Also, the release results should provide a firmer basis for estimating the contribution of shock-produced $\mathrm{CO}_{2}$ to an evolving atmosphere.

\section{Experimental Details and Data Reduction}

The aragonite samples used in this study were pseudo-hexagonal twinned crystals collected by A. Jones near Minglanilla, Spain. The doubly terminated prisms, formed by an intergrowth of three individuals twinned on the (110) plane, display an approximately hexagonal cross section with small reentrant angles often appearing as prism faces at the twin boundaries. Guinier camera $X$ ray analysis verified the identity of the crystals and microprobe analysis indicated a relatively pure $\mathrm{CaCO}_{3}$ composition (see Table 1).

Crystals with a minimum of cracking and discoloration (presumably due to iron and/or manganese), and measuring 15 to $20 \mathrm{~mm}$ in width were cut into 3- to 4-mm-thick sections and lapped to within uniform thickness tolerances of $0.1-0.3 \%$ (i.e., $\pm 3-10 \mu \mathrm{m}$ ). Archimedean densities were determined using reagent grade toluene as a solvent and the temperature corrections of Berman [1939]. Individual density measurements varied by $\pm 0.001 \mathrm{~g} / \mathrm{cm}^{3}$ while the average density for all 12 samples was $2.928 \mathrm{~g} / \mathrm{cm}^{3}$ with a standard deviation of $0.003 \mathrm{~g} / \mathrm{cm}^{3}$. The close agreement between this measured average density and the $X$ ray density of $2.930 \mathrm{~g} / \mathrm{cm}^{3}$ is probably due to a fortuitous cancellation of the effects of impurities and cracks. Owing to the irregular shape of the crystal sections used in the experiment, bulk density determinations were not performed each time. To obtain an approximate measure of sample porosity, a rectangle was cut from an aragonite crystal and lapped to within dimensional tolerances of $0.1 \%$; the porosity determined from this measurement was $1.7 \%$.

The samples were then mounted on either $2024 \mathrm{Al}$ or Ta driver plates with the $c$ axes, as determined 
TABLE 1. Microprobe Analysis of Aragonite Crystals

\begin{tabular}{lc}
\hline Oxide & Weight Percent* \\
\hline $\mathrm{CaO}$ & 54.69 \\
$\mathrm{SrO}$ & 0.85 \\
$\mathrm{P}_{2} \mathrm{O}_{5}$ & 0.04 \\
$\mathrm{CO}_{2}$ & 43.24 \\
$\mathrm{MnO}$ & trace \\
$\mathrm{Na}_{2} \mathrm{O}$ & trace \\
FeO & trace \\
Total & 98.82 \\
\hline
\end{tabular}

*Average of 5 analyses by A. Chodos, California Institute of Technology.

by crystal morphology, orlented perpendicular to the plate (i.e., parallel to the shock propagation direction). Arrays of five lexan mirrors were, in turn, mounted on the sample and the driver plate; care was taken to position the mirrors, particularly the inclined wedge, away from cracks in the sample. The entire sample assembly is pictured in Figure 1a. A 40-mm propellant gun, described by Ahrens et al. [1971] was used to accelerate lexan projectiles fitted with either $2024 \mathrm{Al}$ or Ta flyer plates to velocities in the range of 0.7 to $2.4 \mathrm{~km} / \mathrm{s}$. Projectile velocities were measured using laser beam obscuration times. Sample and buffer mirror shock velocities were obtained from observations of shock-induced loss of mirror reflectivity at successive reflective surfaces as recorded by a rotating-mirror streak camera; an example of such a streak record is shown in Figure Ib.

Pressure-particle velocity and pressure-density states on the sample Hugoniot were calculated from measured projectile and sample shock velocities and known equations of state of $2024 \mathrm{Al}$ and $\mathrm{Ta}$ [McQueen et al., 1970] by use of the Rankine-Hugonlot equations and the impedance-match procedure [Rice et al., 1958]. For experiments in which a two-wave structure was detected, the free-surface approximation [Walsh and Christian, 1955] was made; i.e., it was assumed that the particle velocity, $u_{p} \approx u_{f s} / 2$, where the free surface velocity, ${ }^{p_{b_{f s}}}$, is obtained from the inclined mirror extinction angle [Ahrens and Gregson, 1964]. The pressure-density state behind the first shock was then calculated from the Rankine-Hugoniot relations. The second shock state was calculated by impedance matching using the velocity of the second shock wave. Loss of reflectivity of the free buffer surface (see Figure lb) allowed calculation of the buffer mirror shock state and, hence, sample partial release state by use of experimental Hugoniot data for lexan [Carter and Marsh, 1980] and the Riemann integral [RIce et al.,' 1958]. Free surface velocities, as determined from inclined wedge extinction angle measurements and the Riemann formulation, provided upper bounds for the postshock zero-pressure density [Lyzenga and Ahrens, 1978].

Results

Experimental results for aragonte Hugoniot and release states are 1isted in Table 2 and presented in particle velocity shock velocity $\left(u_{p}, U_{s}\right)$ and density-pressure $(\rho$, P) diagrams in Figures 2 and 3 , respectively.

In six of the experimental shot records, a two-wave structure, such as that displayed in Figure lb, was observed. Three of these double-shock experiments, shots 383,402 , and 498, are interpreted as representing an elastic to plastic shock transition. (It is also possible that shot 498 represents a phase transition occurring at $3.3 \mathrm{GPa}$. However, due to the lack of any corroborative evidence, it will be grouped, for discussion purposes, with the two lowest pressure experiments.) Comparing the shock velocity of the first wave to the longitudinal wave velocity along the $c$ axis of aragonite identifies this first wave as elastic. The only single crystal data for aragonite are those of voigt [1910]. (Bayuk et al. [1974] report polycrystalline aragonite results.) From the elastic stiffness ( $\left.c_{33}\right)$ listed in Voigt's work, a compressional wave velocity along the $c$ axis is computed from the appropriate equation for an orthorhombic crystal:

$$
v_{P}^{c \text { axis }}=\sqrt{c_{33} / \rho}=5.39 \mathrm{~km} / \mathrm{s}
$$

This agrees well with our recent ultrasonic measurement: $v_{\mathrm{P}}^{\mathrm{c}}$ axis $=5.39 \pm 0.035 \mathrm{~km} / \mathrm{s}$ [Kondo, personal communication, 1981]. The observed shock velocities of the assumed elastic wave, ranging from 5.67 to $6.00 \mathrm{~km} / \mathrm{s}$, are, as expected [Davison and Graham, 1979], slightly greater than the ultrasonically measured value. An additional argument for the interpretation of these velocities as elastic comes from the agreement of their corresponding shock pressures, 1.8 to 3.3 GPa, with Hugoniot elastic limit pressures of 1.5 to $2.5 \mathrm{GPa}$ determined for single crystal calcite by Ahrens and Gregson [1964].

As seen in Figure 3, the deformational shock states following the elastic wave, indicated by an asterisk, are considerably displaced from the aragonite Hugoniot, as defined below $8 \mathrm{GPa}$ by six first arrival states both in the elastic and plastic regime (specifically, first arrivals in shots $382,383,402,423,498$, and 499). However, in double-shock experiments where the first wave is in the plastic regime (shots 382, 423, and 499), second arrival shock states (double asterisks in Figure 3) are consistent with both the low pressure Hugoniot, as defined in the last sentence, and the high pressure (above $17 \mathrm{GPa}$ ) Hugoniot. Thus, the deformational shock states indicated by asterisks in Figure 3 are anomalous with respect to all other experimental points. The reason for these deviations may lie in some undetermined phenomena associated with the elastic to plastic shock transition.

On a shock velocity-particle velocity plot, data for the first deformational waves, from those double-wave experiments in which both shock states are in the plastic regime (shots 382, 423, and 499), form a cluster at $U_{s}$ values greater than 


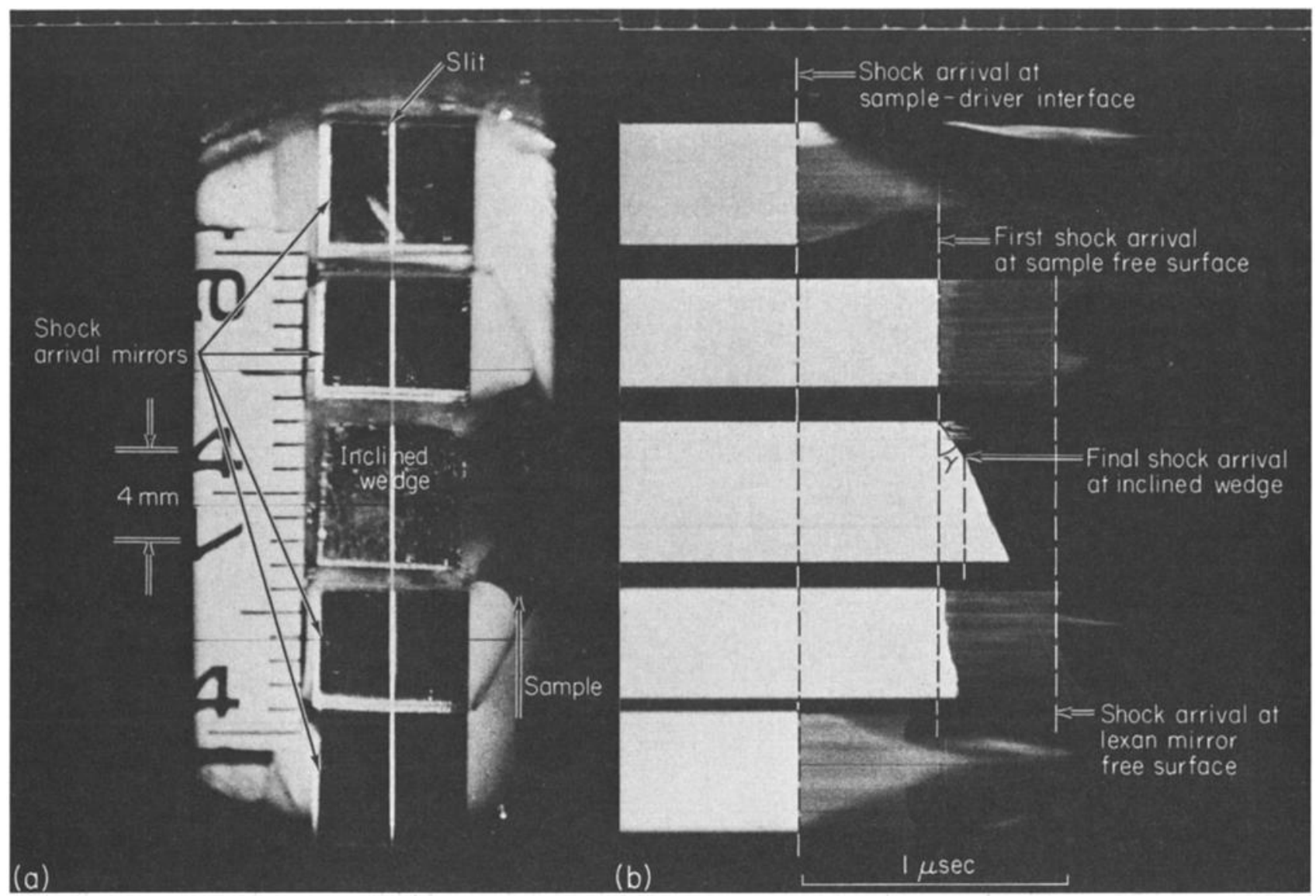

F1g. 1. (a) St111 photograph taken through streak camera showing Imaging slit position. (b) Streak image demonstrating two-wave structure recorded by inclined wedge.

those attributed to the elastic wave, and at low $u$ values (1abeled 'phase transitions' in Figure 2). As seen on the pressure-density plot (Figure 3), two of these values form a distinct cusp at $\sim 7.5 \mathrm{GPa}$, which appears to divide the aragonite Hugoniot into a decidedly steeper (albeit poorly defined) low pressure part and a well-defined initially shallower high pressure part. On the basis of these observations, a phase change in aragonite is tentatively inferred to occur between shock pressures of 5.5 to $7.6 \mathrm{GPa}$.

As already mentioned, several aspects of the low pressure data remain enigmatic. It would appear from Figure 2 that $U_{s}-u_{p}$ values from the second wave arrivals in the six double-wave experiments together outline a poorly defined general trend. Such coincidence, however, would be unexpected in 1ight of the interpretation that three of these points (with the lowest $u_{p}$ values) correspond to an intermediate shock state (following the elastic state), while the other three represent some higher pressure phase. The six second wave arrival points were fit to provide the linear least squares relationship:

$$
\mathrm{U}_{\mathrm{s}}=3.77+2.52 \mathrm{u}_{\mathrm{p}} \mathrm{r}^{2}=0.81
$$

where $3.77 \mathrm{~km} / \mathrm{s}$ and 2.52 represent the constants $c_{o}$ and $s$, respectively, of the $\mathrm{U}_{\mathrm{s}}-\mathrm{u}_{\mathrm{p}}$ Hugoniot representation, and $r^{2}$ is the square of the correlation coefficient. The intercept of $3.77 \mathrm{~km} / \mathrm{s}$ is comparable to the bulk sound velocity of $4 \mathrm{~km} / \mathrm{s}$ derived from the bulk modulus given by Voigt [1910]. Correcting the data for sample compression or wave interaction effects would move the points in Figure 2 to slightly lower $U_{s}$ and/or higher $u$ values. Due to the minimal effect of such ad justments [see, e.g., Ahrens et al., 1968], the large amount of scatter in our data, and the ambiguity in the constitutive relation of aragonite, the data are reported here without such correction. Further justification for the fit of (2) will be provided by the comparison of aragonite and calcite low pressure data (next section).

For particle velocities above $1 \mathrm{~km} / \mathrm{s}$, the $\mathrm{U}_{\mathrm{s}}-\mathrm{u}_{\mathrm{p}}$ data from a consistent set are described by the linear regression

$$
\mathrm{U}_{\mathrm{s}}=5.02+1.30 \mathrm{u}_{\mathrm{p}} \mathrm{r}^{2}=0.99
$$

(Because of an unclear photographic record, shot 393 results are not included in this fit.) As seen in Figure 2, this latter trend is distinct from that observed at particle velocities below $1 \mathrm{~km} / \mathrm{s}$. The shift to a shallower slope, i.e., a smaller $s$ value, above a particle velocity of $1 \mathrm{~km} / \mathrm{s}$ is similar to the pattern exhibited by many silicate minerals in mixed phase regimes [McQueen et a1., 1967]. Further speculation on the higher pressure half of the aragonite Hugoniot and its relation to that of calcite will be presented in the next section.

Partially released states achieved by 
TABLE 2. Sumary of Hugoniot

\begin{tabular}{|c|c|c|c|c|c|c|c|}
\hline \multirow[b]{2}{*}{ Shot } & \multirow[b]{2}{*}{$\begin{array}{l}\text { F1yer/ } \\
\text { Driver } \\
\text { Material }\end{array}$} & \multirow[b]{2}{*}{$\begin{array}{l}\text { Projectile } \\
\text { Velocity, } \\
\text { km/s }\end{array}$} & \multirow[b]{2}{*}{$\begin{array}{l}\text { Initial } \\
\text { Density, } \\
\mathrm{g} / \mathrm{cm}^{3}\end{array}$} & \multicolumn{4}{|c|}{ Hugoniot state* } \\
\hline & & & & $\begin{array}{c}\text { Shock } \\
\text { Velocity } \\
\text { km/s }\end{array}$ & $\begin{array}{l}\text { Particle } \\
\text { Velocity, } \\
\mathrm{km} / \mathrm{s}\end{array}$ & $\begin{array}{c}\text { Pressure, } \\
\text { GPa }\end{array}$ & $\begin{array}{c}\text { Density, } \\
{\mathrm{g} / \mathrm{cm}^{3}}^{3}\end{array}$ \\
\hline \multirow[t]{2}{*}{382} & $2024 \mathrm{Al}$ & 1.194 & 2.925 & $6.26^{\dagger}$ & $0.41^{\dagger}$ & $7.45^{\dagger}$ & $3.13^{\dagger}$ \\
\hline & & \pm 0.005 & \pm 0.001 & $\begin{array}{r} \pm 0.04 \\
4.71\end{array}$ & $\begin{array}{r} \pm 0.02 \\
0.60\end{array}$ & $\begin{array}{l} \pm 0.2 \\
10.23\end{array}$ & $\begin{array}{r} \pm 0.01 \\
3.27\end{array}$ \\
\hline \multirow[t]{2}{*}{383} & 2024 Al & $\begin{array}{r}0.782 \\
\pm 0.005\end{array}$ & $\begin{array}{r}2.929 \\
\pm 0.001\end{array}$ & $\begin{array}{c} \pm 0.04 \\
6.00 \ddagger \\
\pm 0.08 \\
4.92\end{array}$ & $\begin{array}{c} \pm 0.02 \\
0.11 \ddagger \\
\pm 0.01 \\
0.40\end{array}$ & $\begin{array}{c} \pm 0.15 \\
1.84 t \\
\pm 0.1 \\
6.18\end{array}$ & $\begin{array}{c} \pm 0.01 \\
2.98 \dagger \\
\pm 0.01 \\
3.18\end{array}$ \\
\hline & & & & $\begin{array}{l}4.992 \\
\pm 0.1\end{array}$ & $\begin{array}{r}0.40 \\
\pm 0.01\end{array}$ & $\begin{array}{l}0.10 \\
\pm 0.2\end{array}$ & $\begin{array}{r}2.10 \\
\pm 0.04\end{array}$ \\
\hline \multirow[t]{2}{*}{393} & $\mathrm{Ta}$ & 1.376 & 2.926 & 6.85 & 1.05 & 20.97 & 3.45 \\
\hline & & \pm 0.005 & \pm 0.001 & \pm 0.09 & \pm 0.01 & \pm 0.3 & \pm 0.01 \\
\hline \multirow[t]{2}{*}{402} & 2024 A1 & 0.934 & 2.923 & 5.78 & 0.14 & 2.33 & 2.99 \\
\hline & & \pm 0.005 & \pm 0.001 & $\begin{array}{c} \pm 0.2 \\
4.98\end{array}$ & $\begin{array}{r} \pm 0.01 \\
0.48\end{array}$ & $\begin{array}{c} \pm 0.4 \\
7.47\end{array}$ & $\begin{array}{r} \pm 0.04 \\
3.22\end{array}$ \\
\hline \multirow[t]{2}{*}{423} & 2024 Al & 1.059 & 2.925 & $\begin{array}{c} \pm 0.3 \\
6.29\end{array}$ & $\begin{array}{r} \pm 0.02 \\
0.30^{\dagger}\end{array}$ & \pm 0.5 & $\begin{array}{r} \pm 0.07 \\
3.07\end{array}$ \\
\hline & & \pm 0.005 & \pm 0.001 & $\begin{array}{r} \pm 0.06 \\
5.61 \\
\pm 0.05\end{array}$ & $\begin{array}{r} \pm 0.02 \\
0.51 \\
\pm 0.01\end{array}$ & $\begin{array}{r} \pm 0.24 \\
9.20 \\
\pm 0.14\end{array}$ & $\begin{array}{r} \pm 0.01 \\
3.20 \\
\pm 0.01\end{array}$ \\
\hline \multirow[t]{2}{*}{491} & $2024 \mathrm{Al}$ & 1.998 & 2.928 & 6.34 & 1.02 & 18.16 & 3.51 \\
\hline & & \pm 0.01 & \pm 0.001 & \pm 0.04 & \pm 0.01 & \pm 0.1 & \pm 0.01 \\
\hline \multirow[t]{2}{*}{494} & $\mathrm{Ta}$ & 1.237 & 2.933 & 6.25 & 0.96 & 17.54 & 3.46 \\
\hline & & \pm 0.005 & \pm 0.001 & \pm 0.04 & \pm 0.01 & \pm 0.16 & \pm 0.01 \\
\hline \multirow[t]{2}{*}{496} & $\mathrm{Ta}$ & 2.414 & 2.928 & 7.40 & 1.83 & 39.74 & 3.89 \\
\hline & & \pm 0.01 & \pm 0.001 & \pm 0.05 & \pm 0.01 & \pm 0.3 & \pm 0.01 \\
\hline 497 & $\mathrm{Ta}$ & 1.736 & 2.932 & 6.75 & 1.33 & 26.32 & 3.65 \\
\hline \multirow[t]{2}{*}{498} & & $\begin{array}{l} \pm 0.01 \\
0.712\end{array}$ & $\begin{array}{r} \pm 0.001 \\
2.930\end{array}$ & $\begin{array}{r} \pm 0.02 \\
5.66\end{array}$ & $\begin{array}{r} \pm 0.01 \\
0.20 \dagger\end{array}$ & $\begin{array}{l} \pm .17 \\
3.26 \ddagger\end{array}$ & $\begin{array}{r} \pm 0.01 \\
3.04 \ddagger\end{array}$ \\
\hline & & \pm 0.005 & \pm 0.001 & $\begin{array}{r} \pm 0.09 \\
4.51\end{array}$ & $\begin{array}{r} \pm 0.01 \\
0.37\end{array}$ & $\begin{array}{c} \pm 0.2 \\
5.58\end{array}$ & $\begin{array}{r} \pm 0.05 \\
3.16\end{array}$ \\
\hline \multirow[t]{2}{*}{499} & 2024 A1 & $\begin{array}{l}1.550 \\
\pm 0.01\end{array}$ & $\begin{array}{r}2.930 \\
\pm 0.001\end{array}$ & $\begin{array}{c} \pm 0.09 \\
6.42 \\
\pm 0.02\end{array}$ & $\begin{array}{c} \pm 0.01 \\
0.41 \\
\pm 0.02\end{array}$ & $\begin{array}{c} \pm 0.5 \\
7.64^{\dagger} \\
\pm 0.3\end{array}$ & $\begin{array}{c} \pm 0.06 \\
3.13^{\dagger} \\
\pm 0.02\end{array}$ \\
\hline & & & & $\begin{array}{r}5.67 \\
+0.03\end{array}$ & $\begin{array}{r}0.76 \\
+0.03\end{array}$ & $\begin{array}{l}13.98 \\
+0.6\end{array}$ & $\begin{array}{r}3.36 \\
+0.2\end{array}$ \\
\hline \multirow[t]{2}{*}{502} & $\mathrm{Ta}$ & 2.063 & 2.932 & $\begin{array}{r}7.05 \\
7.05\end{array}$ & $\begin{array}{r}1.58 \\
1.58\end{array}$ & 32.53 & 3.78 \\
\hline & & \pm 0.01 & \pm 0.001 & \pm 0.02 & \pm 0.01 & \pm 0.18 & \pm 0.01 \\
\hline
\end{tabular}

*Final shock state unless otherwise noted.
tintermediate deformational shock state.

rarefaction wave propagation into the aragonite samples from the buffer-sample interface together with calculated maximum postshock densities achieved on complete release are plotted in pressure-density space in Figure 4. Two distinct trends are evident. Release paths originating at Hugoniot states at or below $\sim 14 \mathrm{GPa}$ are consistently steeper than the Hugoniot at these pressures, and the corresponding maximum postshock densities suggest density increases upon complete release of up to $10 \%$. (For clarity, release paths for the three lowest pressure Hugoniot points are not shown.) Steep release adiabats, from shock pressures above the suspected onset of a phase transformation, have been observed for a number of silicates, including quartz [Grady et al., 1974], plagioclase feldspar [Ahrens et al., 1969a,b], and olivine [Jackson and Ahrens, 1979], and have been interpreted to indicate retention of the denser high pressure phase during the inftial stages of unloading. The same interpretation may be invoked for araogonite released from pressures between 5 and $14 \mathrm{GPa}$.

With one exception, shallow release paths are observed upon unloading from Hugonlot shock pressures above $17 \mathrm{GPa}$. The one exception, at $\sim 26 \mathrm{GPa}$, displays a slope approximately parallel to that of the Hugoniot. Partial vaporization upon release might be expected to produce the observed release paths. Whether or not the phenomena can occur under the pressure-temperature states achieved upon unloading will be discussed in the next section. The calculated maximum postshock densities for those high pressure experiments do not form an internally consistent set; i.e., there is no continuous relationship 


\begin{tabular}{|c|c|c|c|c|c|}
\hline \multicolumn{4}{|c|}{ Partial Release State } & \multicolumn{2}{|c|}{$\begin{array}{l}\text { Zero-Pressure } \\
\text { Release State }\end{array}$} \\
\hline $\begin{array}{l}\text { Buffer } \\
\text { Shock } \\
\text { Velocity, } \\
\text { km/s } \\
\end{array}$ & $\begin{array}{l}\text { Particle } \\
\text { Velocity, } \\
\text { km/s }\end{array}$ & $\begin{array}{c}\text { Pressure, } \\
\text { GPa }\end{array}$ & $\begin{array}{l}\text { Density, } \\
\mathrm{g} / \mathrm{cm}^{3}\end{array}$ & $\begin{array}{c}\text { Free } \\
\text { Surface } \\
\text { Velocity, } \\
\text { km/s }\end{array}$ & $\begin{array}{c}\text { Maximura } \\
\text { Postshock } \\
\text { Density, } \\
\mathrm{g} / \mathrm{cm}^{3} \\
\end{array}$ \\
\hline $\begin{array}{r}3.53 \\
\pm 0.04\end{array}$ & $\begin{array}{r}0.76 \\
\pm 0.02\end{array}$ & $\begin{aligned} & 3.23 \\
& \pm 0.1\end{aligned}$ & $\begin{array}{l}3.23 \\
\pm 0.1\end{array}$ & $\begin{array}{r}1.13 \\
\pm 0.02\end{array}$ & $\begin{array}{r}3.00 \\
\pm 0.02\end{array}$ \\
\hline $\begin{array}{c}2.98 \\
\pm 0.05 \\
5.38 \\
\pm 0.2\end{array}$ & $\begin{array}{r}0.41 \\
\pm 0.03 \\
1.94 \\
\pm 0.1\end{array}$ & $\begin{array}{l}1.47 \\
\pm 0.1 \\
12.51 \\
\pm 1.3\end{array}$ & $\begin{array}{c}3.18 \\
\pm 0.1 \\
2.60 \\
\pm 0.3\end{array}$ & $\begin{array}{r}0.93 \\
\pm 0.01 \\
1.68 \\
\pm 0.01\end{array}$ & $\begin{array}{r}2.78 \\
\pm 0.01 \\
3.24 \\
\pm 0.04\end{array}$ \\
\hline $\begin{aligned} & 3.29 \\
& \pm 0.1\end{aligned}$ & $\begin{array}{r}0.61 \\
\pm 0.06\end{array}$ & $\begin{aligned} & 2.40 \\
\pm & 0.3\end{aligned}$ & $\begin{array}{l}3.19 \\
\pm 0.1\end{array}$ & $\begin{array}{r}0.80 \\
\pm 0.02\end{array}$ & $\begin{array}{r}3.09 \\
\pm 0.02\end{array}$ \\
\hline $\begin{array}{r}3.48 \\
\pm 0.1 \\
4.67 \\
\pm 0.05 \\
4.97 \\
\pm 0.16 \\
6.54 \\
\pm 0.01 \\
5.41 \\
\pm 0.03\end{array}$ & $\begin{array}{r}0.74 \\
\pm 0.09 \\
1.70 \\
\pm 0.06 \\
1.68 \\
\pm 0.1 \\
2.68 \\
\pm 0.01 \\
1.96 \\
\pm 0.02\end{array}$ & $\begin{array}{l}3.06 \\
\pm 0.5 \\
10.20 \\
\pm 0.5 \\
10.01 \\
\pm 1.9 \\
21.00 \\
\pm 0.4 \\
12.72 \\
\pm 0.22\end{array}$ & $\begin{array}{c}3.12 \\
\pm 0.1 \\
2.91 \\
\pm 0.1 \\
2.78 \\
\pm 0.22 \\
3.38 \\
\pm 0.15 \\
3.30 \\
\pm 0.05\end{array}$ & $\begin{array}{r}1.02 \\
\pm 0.02 \\
2.58 \\
\pm 0.01 \\
1.87 \\
\pm 0.01 \\
4.03 \\
\pm 0.01 \\
2.68 \\
\pm 0.01\end{array}$ & $\begin{array}{r}2.94 \\
\pm 0.02 \\
2.39 \\
\pm 0.04 \\
2.98 \\
\pm 0.03 \\
2.64 \\
\pm 0.15 \\
2.92 \\
\pm 0.04\end{array}$ \\
\hline $\begin{aligned} & 2.89 \\
& \pm 0.1\end{aligned}$ & $\begin{array}{r}0.36 \\
\pm 0.06\end{array}$ & $\begin{array}{r}1.23 \\
\pm 0.26\end{array}$ & $\begin{array}{r}3.16 \\
\pm 0.05\end{array}$ & $\begin{array}{r}0.76 \\
\pm 0.02\end{array}$ & $\begin{array}{r}2.91 \\
\pm 0.05\end{array}$ \\
\hline $\begin{array}{r}3.93 \\
\pm 0.01 \\
5.98 \\
\pm 0.04\end{array}$ & $\begin{array}{r}1.02 \\
\pm 0.01 \\
2.33 \\
\pm 0.03\end{array}$ & $\begin{array}{l}4.78 \\
\pm 0.4 \\
16.64 \\
\pm 0.29\end{array}$ & $\begin{array}{r}3.28 \\
\pm 0.05 \\
3.33 \\
\pm 0.04\end{array}$ & $\begin{array}{r}1.43 \\
\pm 0.02 \\
2.86 \\
\pm 0.05\end{array}$ & $\begin{array}{r}3.22 \\
\pm 0.02 \\
3.17 \\
\pm 0.05\end{array}$ \\
\hline
\end{tabular}

between shock pressure and the zero-pressure density. In addition, two of the zero-pressure density values (shots 393 and 494) are inconsistent with the partially released states. The zero-pressure density values that are consistent with the partially released states suggest distentions upon complete unloading of up to $\sim 20 \%$.

Discussion of Aragonite Results and Comparison with Calcite Hugoniots

In this section, aragonite and calcite Hugoniot data are compared and used to draw some general conclusions on the shock compression and release behavior of carbonates.

The aragonite and calcite Hugonlots are plotted together in Figure 5. The single crystal calcite $\left(\rho=2.71 \mathrm{~g} / \mathrm{cm}^{3}\right)$ Hugoniot [Ahrens and Gregson,
1964; Ahrens et al., 1966] displays an orientationally dependent HEL between 1.8 and $2.4 \mathrm{GPa}$ and a serles of three, or possibly four, cusps, indicative of phase transitions, below $\sim 10 \mathrm{GPa}$. It is the cut calcite Hugoniot that is drawn in Figure 5; above approximately $10 \mathrm{GPa}$, this curve is representative of $a$ and $b$ cut calcite Hugoniot data as well. The authors relate two of these cusps to the calcite I to II and II to III transitions observed in static high pressure experiments [Bridgman, 1939; Singh and Rennedy, 1974]. In a detailed shock compression study of the low pressure phase changes in calcite, Grady et al. [1978] obtained stress-particle velocity profiles for two limestones and a marble which indicated the occurrence of one phase transition between 0.6 and $1.2 \mathrm{GPa}$ and another beginning at $2.4 \mathrm{GPa}$; their interpretation of the first transition (calcite I 


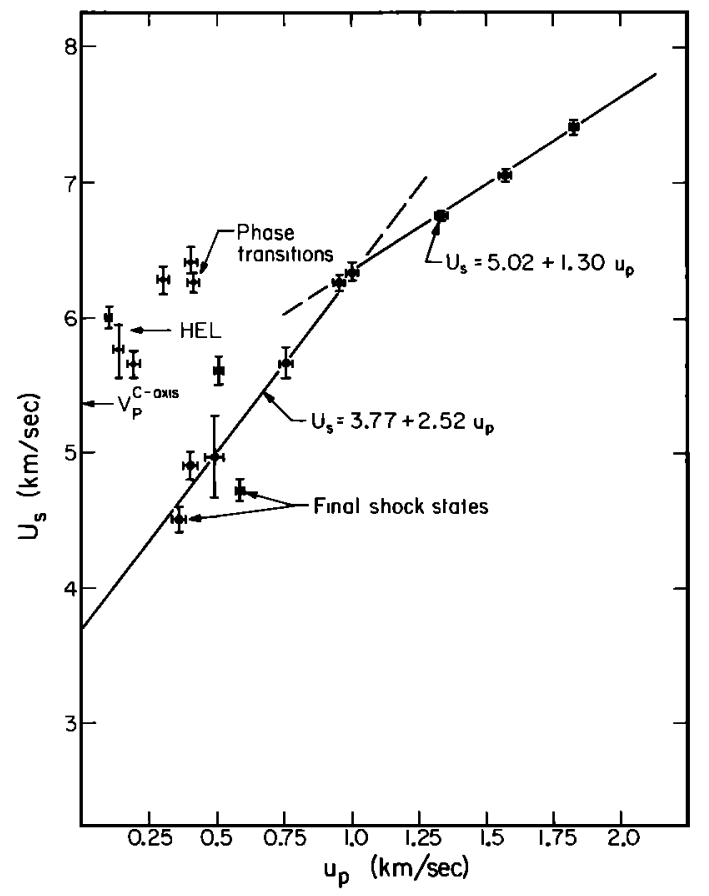

Fig. 2. Aragonite Hugoniot data in the ( $u_{p}$, $U_{s}$ ) plane. Large dots represent final shock states. Elastic and intermediate shock states are labeled 'HEL' and 'phase transitions,' respectively.

to II) as displacive agrees with the static compression results of Merril1 and Bassett [1975]. As previously noted, the aragonite Hugoniot has a HEL at $2.5 \pm 0.8 \mathrm{GPa}$ and a cusp of $6.6 \pm 1 \mathrm{GPa}$. Unfortunately, static compression data on aragonite are too limited to aid in confirmation or characterization of the $6.6-\mathrm{GPa}$ transition. Neither the volume compression stud'es of Bayuk et al. [1974] to $1.5 \mathrm{GPa}$ nor the aiamond anvil experiments of Jamieson [1957] to $2.4 \mathrm{GPa}$ revealed any phase changes in aragonite at or below these pressures. Based on analogies with the calcite phase dlagram and with the known phase relations of $\mathrm{KNO}_{3}$, an 1so-structural analogue of $\mathrm{CaCO}_{3}$ [Rapoport, 1966], we might speculate that the $6.6 \pm 1 \mathrm{GPa}$ aragonite transition is displacive in nature, possibly involving rotation of carbonate groups and/or translation of calcium atom planes. Resolution of this issue, however, requires static high pressure experiments.

Above approximately $10 \mathrm{GPa}$, the Hugoniots of calcite and aragonite are, within the uncertainties in the data, indistinguishable in the pressure-density plane. However, a significant change in the $U_{s}-u_{p}$ plots of both polymorphs is observed at corresponding pressures greater than $10 \mathrm{GPa}$. Our aragonite $\mathrm{U}_{\mathrm{s}}-\mathrm{u}_{\mathrm{p}}$ data, together with that of nonporous and porous polycrystalline calcite, are presented in Figure 6; fits for the various data sets are summarized in Table 3. Note first of all the similarity in the slope of the fits to our aragonite and to the Adadurov et a1. [1961] marble data at low (below $\sim 1 \mathrm{~km} / \mathrm{s}$ ) particle velocities, which further reinforces our fit to the very scattered low pressure aragonite data. At particle velocities of 0.9 and $1.0 \mathrm{~km} / \mathrm{s}$, the $U_{s}-u_{p}$ slopes of calcite
(Adadurov et a1. data) and aragonite, respectively, undergo a shift to shallower values within $2 \%$ of each other. In fact, the slopes of a11 the carbonate data above $u_{p} \approx 1 \mathrm{~km} / \mathrm{s}$ are subparallel. This pattern is typically displayed by data sets for materials of varying porosities [see, e.g., Carter and Marsh, 1980] whereby increasingly porous sample $\mathrm{U}_{\mathrm{s}}-\mathrm{u}_{\mathrm{p}}$ fits lie at lower $U_{s}$ values. Also, the apparent shift of the slope break toward higher $u_{p}$ values with increasing $\mathrm{CaCO}_{3}$ starting density is consistent with the observations made by Jackson and Ahrens [1979] on porous forsterite data. They speculate that increased internal energies at greater material porosities facilitate the onset of phase transitions at lower shock pressures.

Although the data presented in Figure 6 point strongly to attainment of an identical structure at high pressures by calcite and aragonite, they do not shed light on the nature of this transition. Three possibilities are (1) transformation to a high pressure phase at 15 and $\sim 18 \mathrm{GPa}$ on the calcite and aragonite Hugoniots, respectively, (2) onset of a mixed phase regime at these same pressures, and (3) incipient melting. With regard to the third interpretation, there are, as discussed by McQueen et al. [1967], no features intrinsic to either a $\mathrm{U}_{\mathrm{s}}-\mathrm{u}_{\mathrm{p}}$ or $\mathrm{P}-\rho$ representation of melting along a Hugoniot that would allow unequivocal identification of this phenomenon. The coincidence of a break in the $U_{s}-u_{p}$ slope with the intersection of the melting curve and the Hugoniot

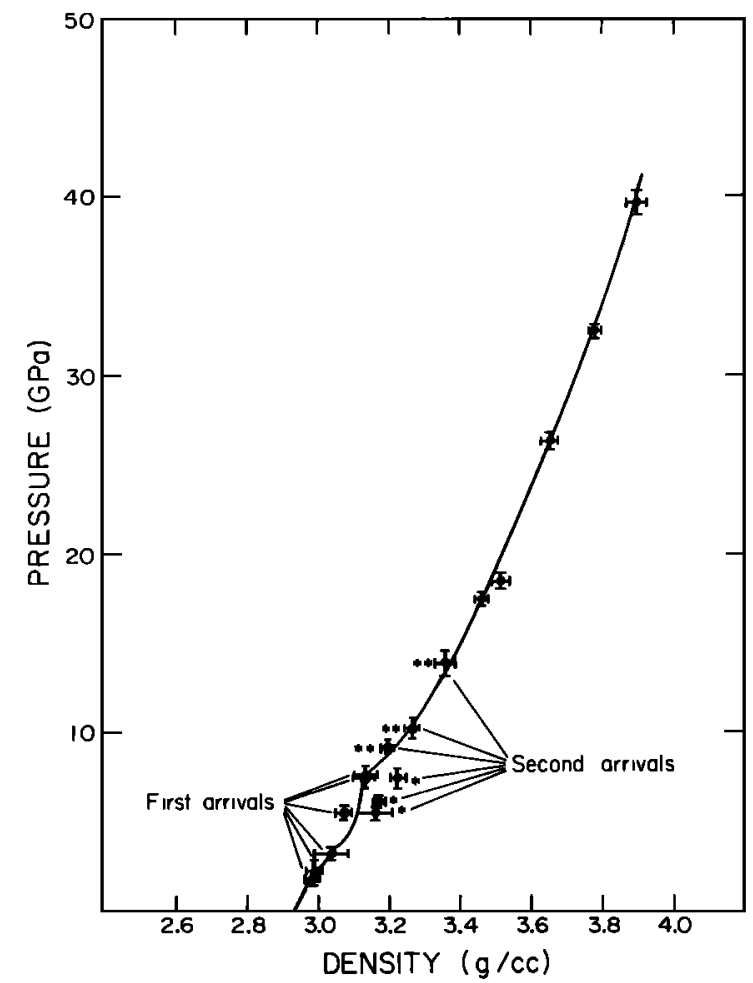

Fig. 3. Aragonite Hugoniot data in the $(\rho, P)$ plane. First and second arrivals refer to experiments in which two shock wave arrivals were recorded. States achleved via an electric shock are labeled with an asterisk, whereas states achieved via a transition shock are labeled with double asterisks. 
would, however, provide some indication of melting during shock compression. In an extensive investigation of phase transitions during shock processes, Carter [1973] showed that minor slope changes in the $\mathrm{U}_{\mathrm{s}}-\mathrm{u}_{\mathrm{p}}$ slopes of $\mathrm{Eu}, \mathrm{Er}$, and $\mathrm{Pb}$ do, in fact, coincide with the calculated melting and experimental Hugoniot curve intersections and concluded that shock melting occurs in these metals. However, the slope change in the a ragonite $U_{s}-u_{p}$ Hugoniot is a major discontinuity, and as will be shown by Hugoniot temperature calculations presented in the following paragraphs, melting does not appear to be a feasible mechanism for the observed behavior. The second possibility is considered because, very typically, in the case of silicate mineral and rock Hugoniots a decrease in $U_{s}-u_{p}$ slope indicates the onset of a mixed phase regime. The trends displayed by the carbonate data are not inconsistent with this interpretation; however, such an assumed mixed phase region would have an uncharacteristically long duration. As seen in Figure 6, even the most porous data of Kalashnikov et al. [1973] do not deviate from linearlty at high $u_{p}$ values, and his nonporous results would indicate the existence of a mixed phase region between 15 and $94 \mathrm{GPa}$; the improbability of such a phenomenon leads to rejection of the second possibility. The first possibility, i.e., transition to a high pressure phase, remains a viable explanation.

To evaluate more thoroughly the feasibility of these speculations, we will attempt to construct an isentrope for the high pressure $\mathrm{CaCO}_{3}$ phase and

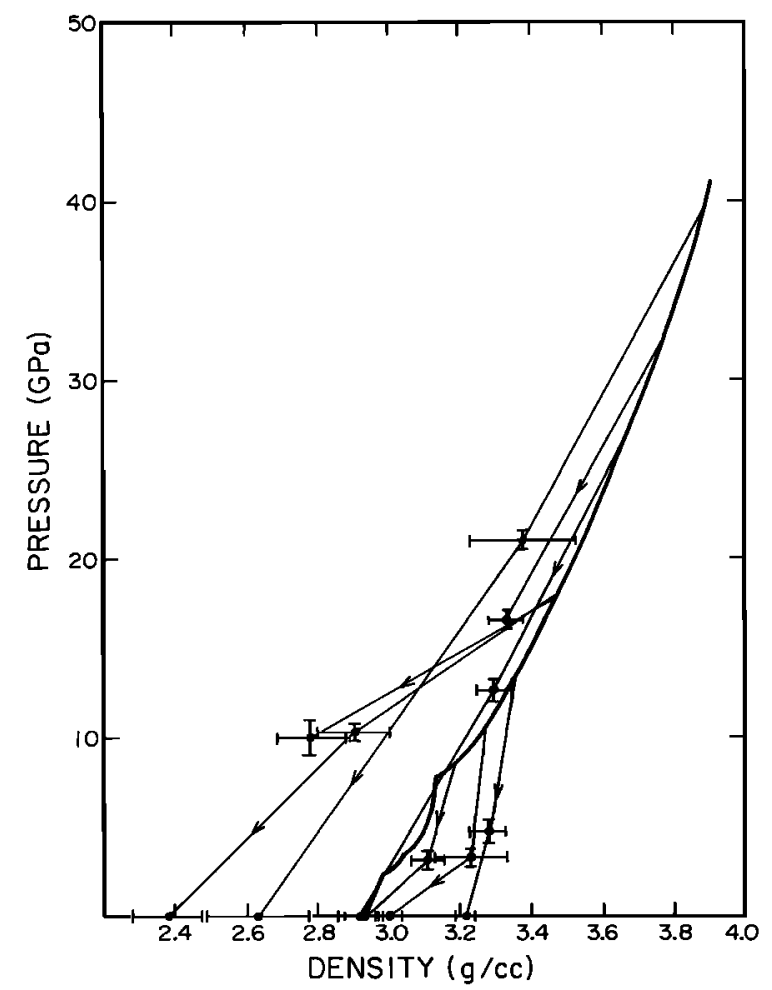

Fig. 4. Aragonite release adiabat states. Intermediate states determined from shock velocity measurements through buffer mirrors and complete release states from inclined wedge extinction angle measurements.

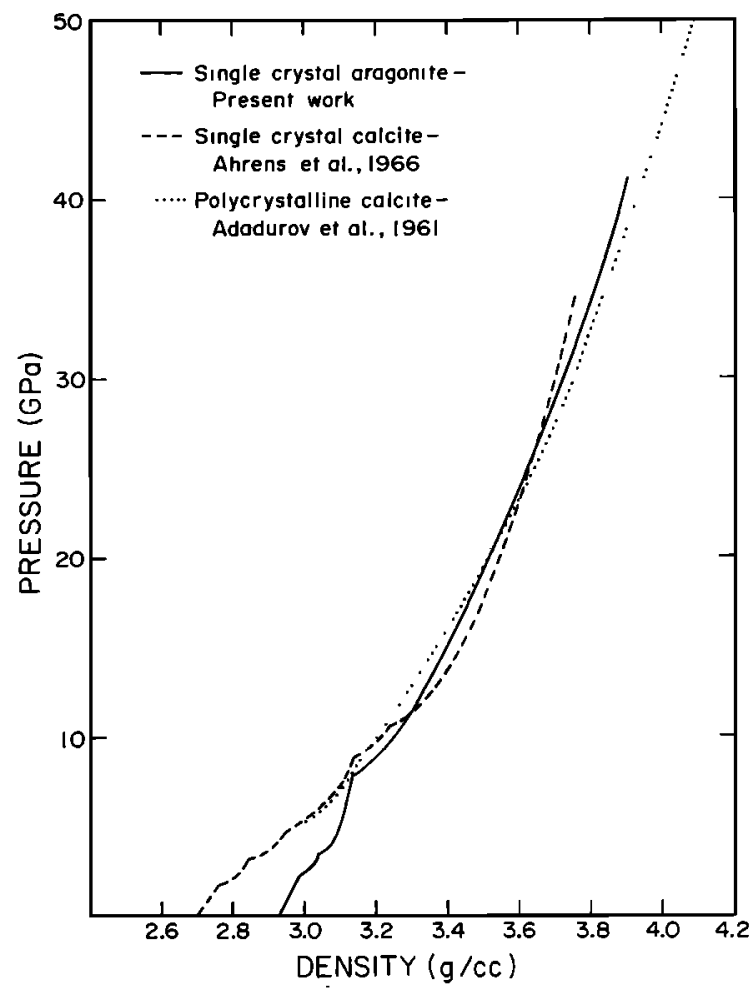

Fig. 5. Hugoniot data for carbonate minerals and rocks, including present aragonite Hugoniot determination.

use this reference curve to calculate temperatures along the calcite and aragonite Hugoniots. A third-order Eulerian (Birch-Murnaghan) formulation is assumed for the high pressure phase isentrope:

$P_{S}(\rho)=\frac{3 K}{2}\left[\left(\rho / \rho_{0}\right)^{7 / 3}-\left(\rho / \rho_{0}\right)^{5 / 3}\right]\left[1+\frac{3}{4}\left\{\left(\rho / \rho_{0}\right)^{2 / 3}-1\right\}\right]$

where $\rho_{0}$ is the zero-pressure density, and $K$ and $K^{\prime}$ are the zero-pressure values of the bulk modulus and first pressure derivative, respectively, of the high pressure phase. This calculated isentrope pressure $P_{S}$ is related to the Hugoniot pressure $\mathrm{P}_{\mathrm{H}}$ at some given $\rho$ through the Mie-Grineisen thermal equation of state:

$$
P_{H}=\left[P_{S}-\gamma \rho\left(E_{S}+E_{T R}\right)\right] /\left[1-\gamma\left(\rho / \rho_{0}^{\prime}-1\right) / 2\right]
$$

where $\rho_{0}^{\prime}, \quad \gamma$, and $E_{T R}$ refer to the initial density of the shocked material, the Grineisen parameter, and the energy of transition between the low and high pressure phases at STP, respectively. $E_{S}$ represents the internal energy change with isentrope compression from the zero-pressure density of the high pressure phase, $\rho_{0}$, to some given density, $\rho$ :

$$
E_{S}=\int_{\rho_{0}}^{\rho} \frac{P_{S}}{\rho^{*}} d \rho^{*}
$$

Using the appropriate input parameters of $\rho_{0}, K$, $K^{\prime}, E_{T R}$, and $\gamma$, it should, therefore, be possible 


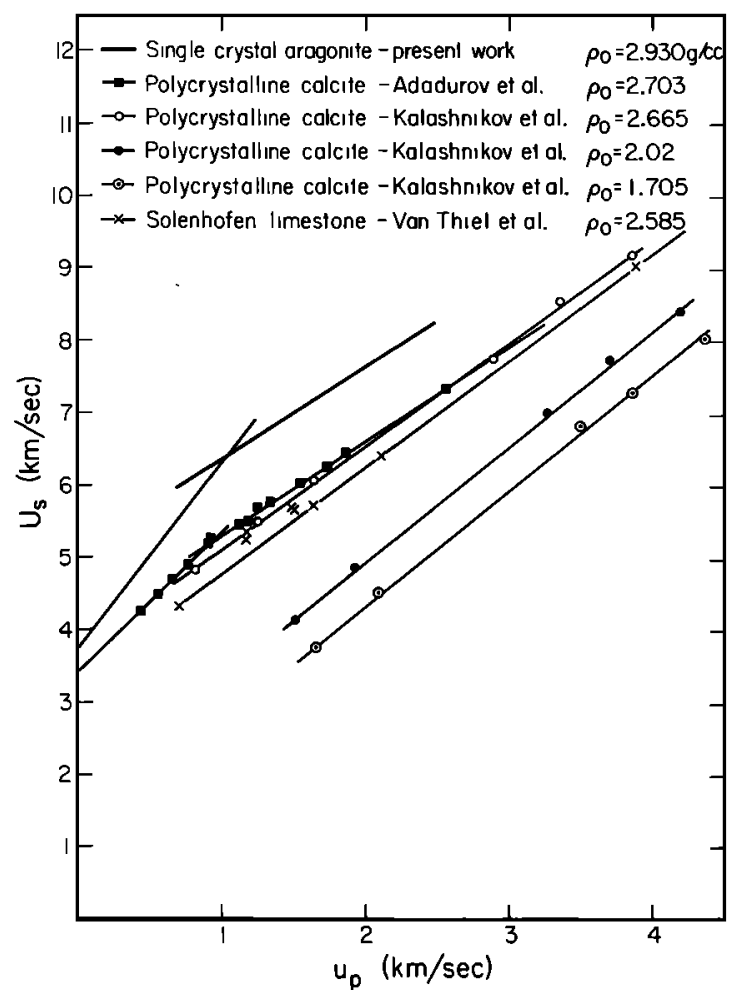

Fig. 6. Comparison of carbonate Hugoniot data, including porous polycrystalline calcite, in the $\left(u_{p}, u_{s}\right)$ plane. Parameters of fits to the data presented in Table 3.

to bring the $P_{H}$ values calculated from (5) into colncidence with the experimentally determined calcite and aragonite Hugoniot.

As already discussed, static compression data that would allow us to characterize the high pressure carbonate phase are not available; $\rho_{0}$, $\mathrm{K}$, and $\mathrm{K}^{\prime}$, therefore, remain unconstrained parameters. The energy of transition to the high pressure phase is also unknown. However, a lower bound to $\mathrm{E}_{\mathrm{TR}}$ may be approximated by the sum of transition energies for the calcite I to II and II to III transitions. Using the data of Singh and Kennedy [1974], an $E_{T R}$ for calcite I to III of

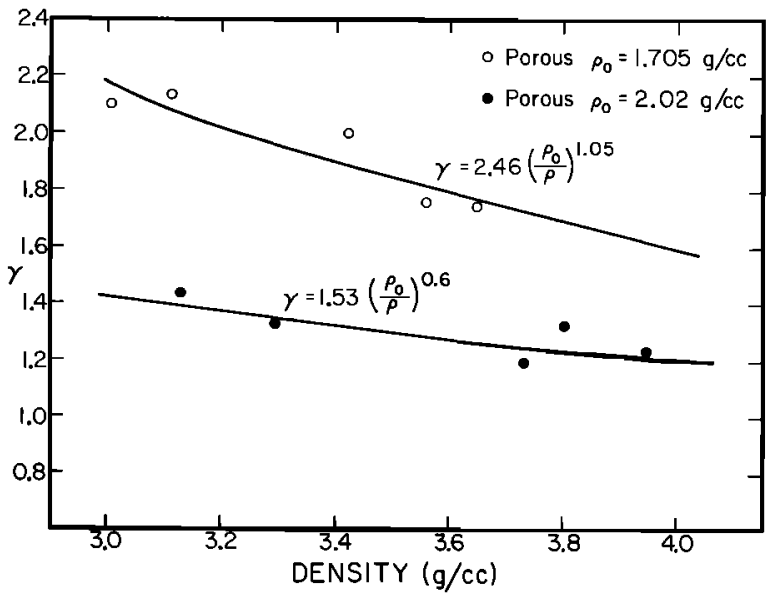

Fig. 7. Density dependence of Grüneisen's $r$, as calculated from porous polycrystalline calcite data of Kalashnikov et al. [1973].

$24 \mathrm{j} / \mathrm{g}$ is calculated. As 1isted by Ahrens et al. [1969a,b], typical estimated $E_{T R}$ for a variety of minerals range from 300 to $\sim 1000 \mathrm{j} / \mathrm{g}$. However, since they refer to transitions occurring at pressures in excess of $30 \mathrm{GPa}$, where the carbonate transitions in question occur at pressures $50 \%$ lower, an upper $E_{T R}$ limit of $200 \mathrm{j} / \mathrm{g}$ (for the carbonate transitions) appears reasonable. In our isentrope model calculations, therefore, $E_{T R}$ was varied between 20 and $200 \mathrm{j} / \mathrm{g}$. form

The Grineisen parameter, assumed to be of the

$$
\gamma=\gamma_{0}\left(\rho_{0} / \rho\right)^{n}
$$

was determined from the two sets of porous calcite data reported by Kalashnikov et al. [1973]. The $\gamma$ calculated for both data sets are plotted as a function of $\rho$ in Figure 7. An attempt was made to use Solenhofen limestone ( $4.6 \%$ porous) data, but the calculated $\gamma$ values showed extreme scatter. If inferences may be drawn from two data sets, the results of Figure 7 point to a direct dependence of $\gamma$ on porosity. Therefore, we used the $\gamma$ formulation determined from the less porous data set, i.e., $\gamma=1.53\left(\rho_{0} / \rho\right)^{0.6}$. The assumption

TABLE 3. Summary of Carbonate Hugoniot Data

\begin{tabular}{|c|c|c|c|c|c|}
\hline Sample & Source & $\rho_{0} \mathrm{~g} / \mathrm{cm}^{3}$ & $c_{0} \mathrm{~km} / \mathrm{s}$ & $\mathbf{s}$ & $\begin{array}{r}\text { Pressure } \\
\text { Range, GPa }\end{array}$ \\
\hline Single crystal aragonite & present work & 2.930 & $\begin{array}{l}3.77 \\
5.02\end{array}$ & $\begin{array}{l}2.52 \\
1.30\end{array}$ & $\begin{array}{r}6 \rightarrow 18 \\
18 \rightarrow 40\end{array}$ \\
\hline Polycrystalline calcite & Adadurov et al. [1961] & 2.703 & $\begin{array}{l}3.40 \\
3.99\end{array}$ & $\begin{array}{l}2.00 \\
1.32\end{array}$ & $\begin{array}{r}5 \rightarrow 13 \\
13 \rightarrow 51\end{array}$ \\
\hline Polycrystalline calcite & Kalashnikov et a1. [1973] & $\begin{array}{l}2.665 \\
2.020 \\
1.705\end{array}$ & $\begin{array}{l}3.70 \\
1.74 \\
1.15\end{array}$ & $\begin{array}{l}1.44 \\
1.61 \\
1.60\end{array}$ & $\begin{array}{l}10 \rightarrow 94 \\
13 \rightarrow 71 \\
10 \rightarrow 59\end{array}$ \\
\hline Solenhofen limestone & van Thiel et al. [1977] & 2.585 & 3.62 & 1.39 & $8 \rightarrow 90$ \\
\hline
\end{tabular}


TABLE 4. $\mathrm{CaCO}_{3} \mathrm{High-Pressure} \mathrm{Phase} \mathrm{Model} \mathrm{Isentrope} \mathrm{Parameters}$

\begin{tabular}{|c|c|c|c|c|}
\hline \multirow{2}{*}{\multicolumn{2}{|c|}{$\rho_{0} \mathrm{~g} / \mathrm{cm}^{3}$}} & \multicolumn{3}{|c|}{$\mathrm{E}_{\mathrm{TR}} \mathrm{J} / \mathrm{g}$} \\
\hline & & 20 & 100 & 200 \\
\hline \multirow[t]{2}{*}{ Aragonite } & 3.0 & $77 / 4.8^{*}$ & $77 / 5.0$ & $79 / 4.8$ \\
\hline & 3.1 & $98 / 4.5$ & $98 / 4.6$ & $98 / 4.8$ \\
\hline \multirow[t]{2}{*}{ Calcite } & 3.0 & $79 / 3.6$ & $79 / 3.7$ & $75 / 4.1$ \\
\hline & 3.1 & $95 / 3.5$ & $92 / 3.8$ & $98 / 3.4$ \\
\hline
\end{tabular}

*Tabulated values represent $\mathrm{K}(\mathrm{GPa}) / \mathrm{K}^{\prime}$.

that $\gamma$ for the high pressure $\mathrm{CaCO}_{3}$ phase is small is also consistent with the close coincidence of the calcite and aragonite Hugoniots at high pressure. Small variations in $\gamma$, however, do not significantly affect the model isentrope calculations.

The self-consistent sets of model parameters that best fit experimental calcite and aragonite Hugoniots are summarized in Table 4. It is evident from this table that varying the initial h1gh pressure phase density by $0.1 \mathrm{~g} / \mathrm{cm}^{3}$ profoundly affects the bulk modulus and first pressure derlvative values in the model calculations. Performing the calculation with $\rho_{\circ}$ greater than $3.1 \mathrm{~g} / \mathrm{cm}^{3}$ would constrain $K$ to very high values, above $100 \mathrm{GPa}$. On the other hand, the calculations are relatively insensitive to changes in $\mathrm{E}_{\mathrm{TR}}$. Therefore, even by allowing an $\mathrm{E}_{\mathrm{TR}}$ of $70 \mathrm{j} / \mathrm{g}$ for the calcite to aragonite transition (a maximum value calculated according to McQueen et al. [1963], assuming a calcite to

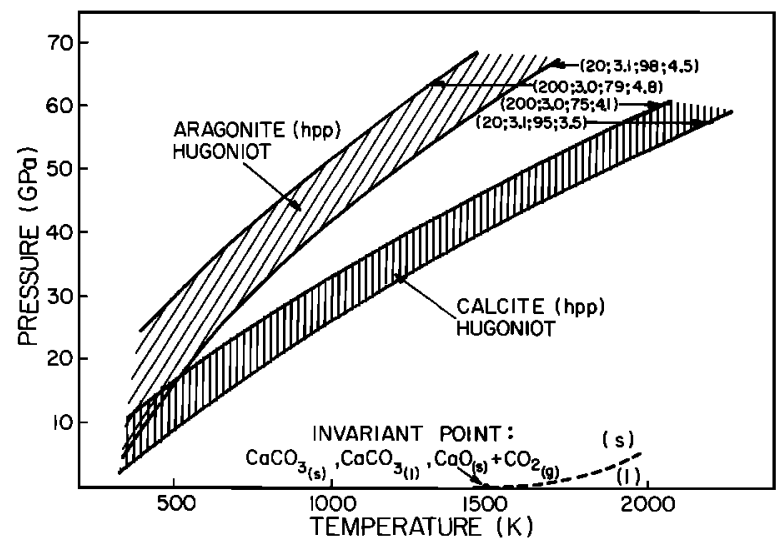

Fig. 8. Pressure versus temperature relation along aragonite and calcite Hugoniots. Numbers In parentheses represent ( $\mathrm{E}_{\mathrm{TR}}: \rho_{\mathrm{O}} ; \mathrm{K} ; \mathrm{K}^{\prime}$ ) values used in model isentrope calculations along which temperature estimates are made. $\gamma$ was assumed to be of the form $\gamma=1.53\left(\rho_{0} / \rho\right)^{0.6}$. Calcite melting curve [Irving and Wy111e, 1973] appears in the right of the graph. aragonite transition at $9 \mathrm{GPa}$ ), it is not possible to force both calcite and aragonite to the same high pressure phase. Nevertheless, the $K / K^{\prime}$ values for both polymorphs (at the same $E_{T R}$, $\rho_{0}$ conditions) are very similar, and transformation of both polymorphs to the same high pressure phase cannot be discounted. In the Hugonlot temperature calculations described in the following paragraph, the entire range of model isentrope parameters presented in Table 4 is considered. from

Temperatures along the Hugoniot are determined

$$
T_{H}=298 \exp \left[\int_{\rho_{0}}^{\rho} \frac{\gamma}{\rho^{*}} d \rho^{*}\right]+\frac{E_{H}-E_{S}}{C_{V}}
$$

The first term in this equation is the temperature rise along the high pressure phase isentrope, and the second is the temperature difference at some density between this calculated isentrope and the (experimenta1) Hugoniot. $\mathrm{E}_{\mathrm{S}}$ is given by (6), and ${ }^{E_{H}}$ by the Rankine-Hugoniot conservation equation

$$
E_{H}-E_{0}=1 / 2\left(P_{0}+P_{H}\right)\left(1 / \rho_{o}^{\prime}-1 / \rho\right)
$$

where the standard $E_{0}$ and $P_{0}$ conditions are taken to be equal to zero and $\rho_{0}^{\prime}$ is the initial density of the shocked material. We assume that the heat capacity at constant volume $C_{V}$ is equal to the Dulong-Petit value of $3 R$, where $R$ is the gas constant. According to experimental heat capacity measurements [Robie et a1., 1978], 90\% of this

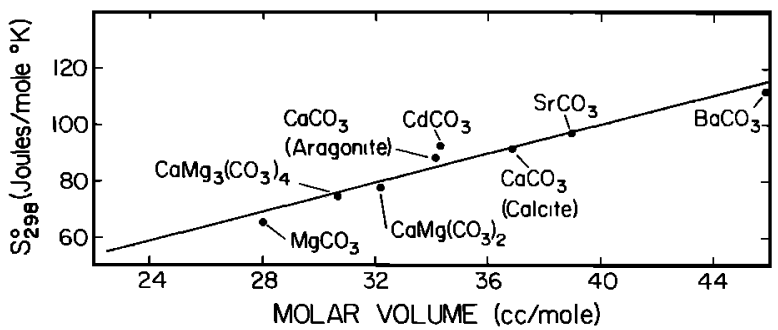

Fig. 9. Plot showing systematic relationship between standard entropy, $s_{298}^{0} 15 \mathrm{~K}$, and molar $\mathrm{s}_{298.15 \mathrm{~K}}$ for speculated high ${ }_{\text {pressure } \mathrm{CaCO}_{3}}$ phase. 


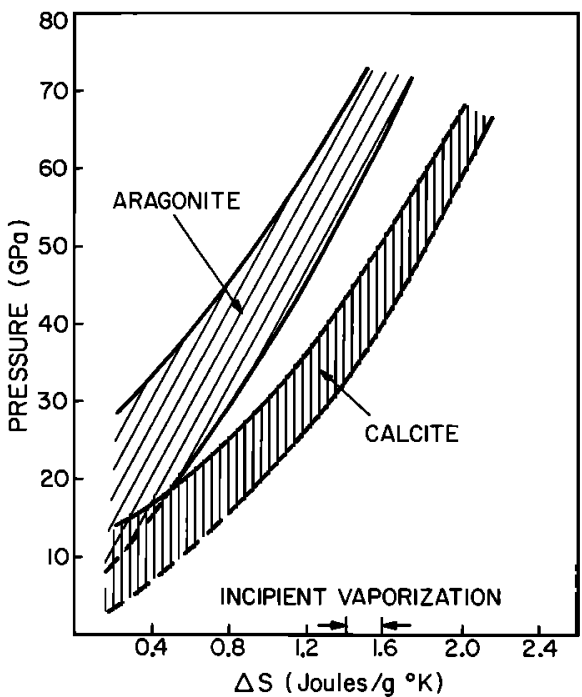

Fig. 10. Calculated postshock entropies, relative to standard state entropy, for aragonite and calcite. Parameters used in calculating upper and lower bounds for each phase correspond to the values presented for the top and bottom curves in Figure 8 . The entropy for complete vaporization, $\Delta S \approx 3 \mathrm{j} / \mathrm{g} \mathrm{K}$, is not achieved at reasonable extrapolations of experimental data.

Dulong-Petit value is achieved by temperatures of $650 \mathrm{~K}$ and $720 \mathrm{~K}$ in calcite and aragonite, respectively; thus, our assumption is justified over most of the calculated temperature range. Calculated calcite and aragonite Hugoniot temperatures for a range of input parameters are presented in Figure 8. The numbers in parentheses refer to the transition energy, initial density, bulk modulus, and first pressure derivatives of the high pressure phase values, respectively, used in the high pressure phase isentrope determinations. The calcite melting curve determined by Irving and Wyllie [1973] is also included in this graph. Any reasonable extrapolation of the melting curve to higher pressures rather decisively speaks agalnst the possibility of melting occurring at $\sim 15$ and $\sim 18 \mathrm{GPa}$ on the calcite and aragonite Hugoniots, respectively.

As noted in the experimental results section, the release adiabats for aragonite indicate a consistent pattern. Release from shock states below $\sim 14 \mathrm{GPa}$ occurs along steep paths and suggests densification of up to $10 \%$ upon complete release, whereas release from pressures above $17 \mathrm{GPa}$ progresses along shallow paths, suggesting vaporization upon unloading. As discussed above, theoretical shock temperatures along the aragonite Hugoniot are insufficient to cause melting. To investigate the possibility of vaporization upon the release of $\mathrm{CaCO}_{3}$ to ambient pressures, the shock entropy criterion was applied [see, e.g., Ze1'dovich and Raizer, 1967; Ahrens and $0^{\prime}$ Keefe, 1972]. Briefly, the method compares the entropy value along the release path with the entropy of vaporization at 1 bar. Since release is an isentropic process, the entropy at a release pressure of 1 bar is the same as that of the Hugoniot state. In turn, the entropy along the
Hugoniot relative to standard state entropy, $\Delta S$, can be determined from the temperature rise between the shock isentrope and the Hugoniot:

$$
\Delta S=\int_{T_{S}}^{T_{H}} \frac{C_{V}}{T} d T
$$

Determination of incipient and complete vaporization entropies (upon release from pressures above the suspected phase change) requires knowledge of the standard state entropy of the high pressure $\mathrm{CaCO}_{3}$ phase. An estimate of $\mathrm{s}_{298.15 \mathrm{~K}}^{0}=0.8 \rightarrow 0.83 \mathrm{j} / \mathrm{g} \mathrm{K}$, corresponding to a high pressure phase $\rho_{0}$ of $3.1+3.0 \mathrm{~g} / \mathrm{cm}^{3}$ respectively, is based on the systematic relationship, shown in Figure 9, between $S_{298,15 K}^{0}$ and the molar volume of carbonates [Robie et al., 1978]. The incipient vaporization criterion involves coincidence of the release state entropy value with the entropy increase achieved in ralsing a material to its vaporization temperature at 1 bar; according to the experimentally determined vaporization curve [Baker, 1962], vaporization of calcite at 1 bar occurs at $1171 \mathrm{~K}$. Complete vaporization entropy is the sum of the entropy gained in raising the material to its vaporization temperature and the dissociation entropy at that temperature. Calculated postshock entropies for calcite and aragonite are presented in Figure 10; entropies for complete vaporization, $\Delta S \approx 3 \mathrm{j} / \mathrm{g} \mathrm{K}$, do not appear to be reached below shock pressures of $\sim 100 \mathrm{GPa}$ for either calcite or aragonite. According to this model, then, minimum shock pressures for incipient vaporization are 33 and $55 \mathrm{GPa}$ for calcite and aragonite, respectively. These values are similar to shock pressures required for vaporization as calculated by Kieffer and Simonds [1980] using the waste heat approximation. The agreement adds support to the contention that $\gamma$ is small.

Thus, although the shock and release state experimental evidence is consistent with the suggested interpretation that vaporization upon release characterizes the behavior of carbonates at shock pressures in excess of $\sim 17 \mathrm{GPa}$, theoretical considerations are in pronounced conflict with this interpretation. Possible causes for this discrepancy might be found by considering shock deformational behavior, on the microstructural scale, of brittle, thermally insulating solids. Grady [1980] and Horie [1980] extensively discuss the role of heterogeneous deformation during shock compression. According to these authors, instabilities intrinsic to shock compression processes result in localized regions of intense deformation and extreme temperature gradients which may persist for some time after passage of the shock wave. Thus, even though equilibrium temperature estimates are well below those required for melting, local 'hot spot' temperatures may be sufficient to melt material in local shear bands. In fact, such zones of intense local deformation have been observed in shock-recovered materials [see, e.g., Jeanloz et al., 1977]. Grady [1980] estimates the intensity of local temperature excursions in several minerals including calcite. According to his calculations, a significant fraction of the melting temperature $\left(\mathrm{T}_{1 \text { ocal }} / \mathrm{T}_{\text {me1t }}>0.5\right)$ is reached when calcite is shocked to a relatively 
modest pressure of $4.4 \mathrm{GPa}$. Although it is difficult to assess the extent to which processes of adiabatic shear and heterogeneous melting influence the Hugoniot results, their effects, at least in a qualitative sense, should be given serious consideration in evaluation of shock compression data.

\section{Summary and Conclustons}

The aragonite Hugoniot to $40 \mathrm{GPa}$ can be summarized as follows. The lower portion of the curve is inferred to display a Hugoniot elastic Iimit between 1.8 and $3.3 \mathrm{GPa}$ and a phase transition, possibly displacive, between 5.5 and $7.6 \mathrm{GPa}$. Above shock pressures of $\sim 10 \mathrm{GPa}$, the density-pressure curve becomes initially shallower and remains smooth to $40 \mathrm{GPa}$; the calcite and aragonite Hugoniots in the 10 to $40 \mathrm{GPa}$ range are, within the limits of experimental error, coincident, suggesting the transformation of both polymorphs to a cammon high pressure phase.

Measured release adiabats for aragonite from shock states below $\sim 14$ GPa show consistently steep initial unloading paths (in the density-pressure plane) and final zero-pressure densities up to $10 \%$ greater than the initial density. Unloading paths from pressures greater than $\sim 17 \mathrm{GPa}$ are unusually shallow, a pattern that is consistent with the interpretation that vaporization occurs upon unloading. Although the experimental results may suggest vaporization upon release from these pressures, theoretical shock temperature and entropy calculations decidedly conflict with this interpretation.

Acknowledgments Tony Jones provided the aragonite crystals used in this study. Helpful discussions with Ken-ichi Kondo and J. Peter Watt are gratefully acknowledged. We thank Raymond Jeanloz and an anonymous reviewer for careful reviews and many helpful comments. This work was supported by NASA grant NGL 05-002-105. Contribution 3507, Division of Geological and Planetary Sciences, California Institute of Technology, Pasadena, California 91125.

\section{References}

Adadurov, G. A., D. B. Balashov, and A. N. Dremin, A study of the volumetric compressibility of marble at high pressures, Bull. Acad. Sci. USSR Geophys. Ser., 5, 463-466, 1961.

Ahrens, T. J., and V. G. Gregșon, Jr., Shock compression of crustal rocks: Data for quartz, calcite, and plagioclase rocks, J. Geophys. Res., 69, 4839-4874, 1964.

Ahrens, T. J., and J. D. $0^{\prime}$ Keefe, Shock melting and vaporization of lunar rocks and minerals, Moon, 4, 214-249, 1972.

Ahrens, T. J., J. T. Rosenberg, and M. V. Ruderman, Dynamic properties of rocks, Rep. DASA 1868, pp. 107-111, Stanford Res. Inst., Meñlo Park, Cal1f., 1966.

Ahrens, T. J., W. H. Gust, and E. B. Royce, Material strength effect in the shock compression of alumina, J. Appl. Phys., 39, 4610-4616, 1968.

Ahrens, T. J., D. L. Anderson, and A. E. Ringwood, Equations of state and crystal structures of high-pressure phases of shocked silicates and oxides, Rev. Geophys. Space Phys., 7, 667-707, 1969a.

Ahrens, T. J., C. F. Petersen, and J. T. Rosenberg, Shock compression of feldspars, J. Geophys, Res., 74, 2727-2746, 1969b.

Ahrens, T. J., J. H. Lower, and P. L. Lagus, Equation of state of forsterite, J. Geophys. Res., 76, 518-528, 1971.

Baker, E. H., The calcium oxide-carbon dioxide system in the pressure range 1-300 atmospheres, Chem. Soc. J., 464-470, 1962.

Bayuk, Y. I., M. P. Volorovich, and G. A. Yefimova, Ultrasonic studies of phase transitions in calcite at high pressures, Izv. Acad. Sci. USSR Phys. Solid Earth, $\underline{8}, 59-62$, 1974.

Berman, H., A torsion microbalance for the determination of specific gravities of minerals Am. Mineral., 24, 435-440, 1939.

Booth, M. C., and H. H. Kieffer, Carbonate formation in Marslike environment, J. Geophys. Res., 83, 1809-1815, 1978.

Bridgman, P. W., The high pressure behavior of miscellaneous minerals, Am. J. Sci., 239, $7-18,1939$.

Carter, W. J., Shock wave techniques for the examination of phase transitions, in Phase Transitions-1973 Proceedings of the Conference on Phase Transitions and Their Applications in Materials Science, edited by L. E. Cross1, Pp. 223-234, Pergamon, New York, 1973.

Carter, W. J., and S. P. Marsh, Hugoniot equation of state of polymers, submitted to $\mathrm{J}$. Chem. Phys., 1980.

Davison, L., and R. A. Graham, Shock compression of solids, Phys. Rep., 55, 255-379, 1979.

Grady, D. E., Shock deformation of brittle solids, J. Geophys. Res., 85, 913-924, 1980.

Grady, D. E., W. J. Murrl, and G. R. Fowles, Quartz to stishovite: Wave propagation in the mixed phase region, J. Geophys. Res., 79, 332-338, 1974.

Grady, D. E., R. E. Hollenbach, and $\mathrm{K}$. W. Schuler, Compression wave studies on calcite rock, J. Geophys. Res., 83, 2839-2849, 1978.

Grieve, R. A. F., and P. B. Robertson, The terrestrial cratering record, 1, Current status of observations, Icarus, 83, 212-229, 1979.

Horfe, Y., Thermodynamics of dislocations and shock compression of solids, Phys, Rev., 21, 5549-5557, 1980.

Huang, W. L., and P. J. Wyllie, Melting relationships in the systems $\mathrm{CaO}-\mathrm{CO}_{2}$ and $\mathrm{MgO}^{-\mathrm{CO}_{2}}$ to 33 kilobars, Geochim. Cosmochim. Acta, 40, 129-132, 1976.

Irving, A. J., and P. J. Wyllle, Melting relationships in $\mathrm{CaO}-\mathrm{CO}_{2}$, Earth Planet. Sci. Lett., 20, 220-225, 1973 .

Jackson, $\overline{I .}$, and T. J. Ahrens, Shock wave compression of single-crystal forsterite, J. Geophys. Res., 84, 3039-3048, 1979.

Jamieson, J. C., Introductory studies of high-pressure polymorphism to 24,000 bars by $X$-ray diffraction with some commments on calcite II, J. Geo1., 65, 334-342, 1957.

Jeanloz, R., T. J. Ahrens, J. S. Lally, G. L. Nord, Jr., J. M. Christie, and A. H. Heuer, Shock-produced olivine glass; First observation, Science, 197, 457-459, 1977.

Kalashnikov, N. G., M. N. Pavlovskiy, G. V. 
Simakov, and R. F. Trunin, Dynamic compressibility of calcite-group minerals, Izv. Acad. Sci. USSR Phys. Solid Earth, 2, 23-29, 1973.

Kieffer, S. W., and C. H. Simonds, The role of volatiles in the impact cratering process, Rev. Geophys. Space Phys., 18, 143-181, 1980.

Lewis, J. S., Venus: Atmospheric and lithospheric composition, Earth planet. Sci. Lett., 10, 73-80, 1970.

Lyzenga, G., and T. J. Ahrens, The relation between the shock-induced free surface velocity and the post-shock specific volume of solids, J. Appl. Phys., 49, 200-213, 1978.

McQueen, R. G., J. N. Fritz, and S. P. Marsh, On the equation of state of stishovite, J. Geophys. Res., 68, 2319-2322, 1963.

McQueen, R. G., S. P. Marsh, and J. N. Fritz, Hugoniot equation of state of twelve rocks, J. Geophys. Res., 72, 4999-5036, 1967.

McQueen, R. G., S. P. Marsh, J. W. Taylor, J. N. Fritz, and $W$. J. Carter, The equation of state of solids from shock wave studies, in High-Velocity Impact Phenomena, edited by $R$. KInslow, Pp. 293-417, Academic, New York, 1970.

Merrill, L., and W. A. Bassett, The crystal structure of $\mathrm{CaCO}_{3}$ (II), a high-pressure metastable phase of calcium carbonate, Acta Crystallogr., Sect. B, 31, 343-349, 1975.
Rapoport, E., Polymorphism and melting in the alkali nitrates to $40 \mathrm{~kb}$ with some comments on the alkaline earth carbonates, J. Geophys. Chem. Solids, 27, 1349-1363, 1966.

Rice, M. H., R. G. McQueen, and J. M. Walsh, Compression of solids by strong shock waves, Solid State Phys., 6, 1-63, 1958.

Robie, R. R., B. $\bar{s}$. Hemingway, and J. R. Fisher, Thermodynamic properties of minerals and related substances at $298.15 \mathrm{~K}$ and 1 bar ( 10 pascals) pressure and at higher temperatures, Geol. Surv. Bull. U.S., 1952, 298-310, 1978.

Singh, A. K., and G. C. Kennedy, Compression of calcite to $40 \mathrm{kbar}$, J. Geophys. Res., 79, 2615-2622, 1974.

Voigt, W., Lehrbuch der Kristallphysik, pp. 410-431, B. A. Teubner, Leipz1g, 1910.

Walsh, J. M., and R. H. Christian, Equation of state of metals from shock wave measurements, Phys. Rev., 1544-1556, 1955.

Ze 'dovich, Y. B., and Y. P. Raizer, Physics of Shock Waves and High-Temperature Hydrodynamic Phenomena, vol. II, Pp. 766-770, Academic, New York, 1967.

(Received October 24, 1980; revised July 24, 1981 ; accepted September 18, 1981). 